\title{
BIOCHEMISTRY QUESTIONS ANALYSIS FROM NATIONAL EXAM OF STUDENT PERFORMANCE (ENADE)
}

Artur Paiva Dos Santos ${ }^{1}$, Marcelle Ferreira Moura ${ }^{1}$, Natalia Lima Barbosa ${ }^{1}$, Magnely Moura Do Nascimento ${ }^{1}$, Hermógenes David De Oliveira²

${ }^{1}$ Centro Universitário Christus, Fisioterapia (Ceará, Brazil), 2 Universidade Federal Do Ceará, Bioquímica (Ceará, Brazil)

INTRODUCTION: The Brazilian National Exam of Student Performance (ENADE) is part of the National System of Higher Education Assessment (SINAES), that was created to evaluate the quality of undergraduate courses and higher education institutions throughout Brazil. Biochemistry is a discipline present in the basic curriculum of the health courses and many students complete their courses without a belief that the basic sciences they have studied will have much relevance to their day-to-day clinical practice. OBJECTIVES: The aim of this work was to analyze the Biochemistry questions from ENADE of the health area courses and to propose an integrated approach that prepares students for lifelong learning. MATERIALS AND METHODS: This work was an exploratory research with a descriptive analysis of the Biochemistry questions of ENADE (2004, 2006, 2007, 2010 and 2013) applied for the courses of Physiotherapy, Medicine, Nutrition, Biomedicine, Physical Education, Nursing, and Pharmacy. Twentyone tests were analyzed and the Biochemistry questions separated by course and according to their integrative view. DISCUSSION AND RESULTS: 28 exams were analysed, It was selected 857 questions from specific component, from which 8.05\% (69 questions) were based on Biochemistry contents. Higher percentage of Biochemistry questions was found in exams of courses Nutrition (30.43\%), followed by Biomedicine (28.98\%), Pharmacy (20.28\%), Physical Education (7.24\%), Medicine (5.79\%), Physiotherapy (4.34\%) and Nursing (2.89\%). Forty-one percent of the questions analysed presented only basic concepts in Biochemistry, $26 \%$ were contextualized, and $33 \%$ were interdisciplinary. CONCLUSION: The results demonstrated the relevance of Biochemistry for the assessment of the quality of undergraduate courses in the health area in Brazil and suggested a profile questions that could be used in Biochemistry classes to introduce an active methodology approach.

Keywords: Question Analysis; Biochemistry; ENADE 